Case Report

\title{
Nontraumatic Laryngeal Fractures: Report of Two Cases and Review of the Literature
}

\author{
Alfredo Santamaría, ${ }^{1}$ Ricardo Alarcón, ${ }^{1}$ Ilson Sepúlveda, ${ }^{2}$ and Felipe Fredes ${ }^{1}$ \\ ${ }^{1}$ ENT-Head and Neck Surgery Service, General Hospital of Concepcion, University of Concepcion School of Medicine, \\ Concepcion, Chile \\ ${ }^{2}$ Radiology Department, ENT-Head and Neck Surgery Service, General Hospital of Concepcion, Concepcion, Chile \\ Correspondence should be addressed to Alfredo Santamaría; alsantamariac@gmail.com
}

Received 15 November 2016; Accepted 21 March 2017; Published 9 April 2017

Academic Editor: Emilio Mevio

Copyright (C) 2017 Alfredo Santamaría et al. This is an open access article distributed under the Creative Commons Attribution License, which permits unrestricted use, distribution, and reproduction in any medium, provided the original work is properly cited.

Laryngeal fractures occur mainly in the context of cervical trauma, hanging, or strangulation. Nontraumatic laryngeal fractures are rare and there are few reports in the literature. We present two cases of nontraumatic laryngeal fractures evaluated in our service.

\section{Introduction}

Laryngeal fractures occur mainly from direct trauma, suicide by hanging, or strangulation [1]. Nontraumatic laryngeal fractures are rare, with 4 cases reported in the literature [2$5]$. We present two cases of nontraumatic laryngeal fractures, the first case after a sneeze attack and the second case after swallowing.

\section{Case Reports}

2.1. Case 1. A 36-year-old male patient presented to the emergency department with severe odynophagia and dysphonia. The patient had no significant prior medical or surgical history, except for a traffic accident 12 years ago resulting in complicated abdominal trauma with no cervical lesions. He reported that the symptoms started two hours ago and had an abrupt onset after a contained sneeze in a work meeting. He reports that after the sneeze he felt a crack in the neck and after that the symptomatology was installed.

It was evaluated in the otolaryngology department, on physical examination, that the oropharynx and neck examination revealed no tonsillar erythema or edema but diffuse tenderness over the thyroid cartilage without subcutaneous emphysema. A nasopharyngolaryngoscopy was performed, in which a left vocal fold hematoma was evidenced with normal vocal fold movement. The study was completed with a computed tomography, observing a left, complete, nondisplaced parasagittal fracture that compromises thyroid cartilage (Figure 1).

It was managed with oral corticosteroids for 7 days and vocal rest for 15 days, achieving complete resolution of symptoms in 21 days. At the 5 -year follow-up, the patient has not had another episode.

2.2. Case 2. A 32-year-old male patient with no significant prior medical or surgical history presented to the otolaryngology service with odynophagia, dysphagia, and dysphonia. The symptoms started six days ago and had an abrupt onset after swallowing and bending over during dinner. He reports that after that he felt a crack in the neck and then the symptomatology was gradually installed.

On physical examination the patient had pain over the thyroid cartilage without subcutaneous emphysema. A nasopharyngolaryngoscopy was performed, in which supraglottic edema with normal vocal fold movement was evidenced. The study was completed with a computed tomography that showed an anterior, left parasagittal, complete nondisplaced thyroid cartilage fracture (Figure 2).

It was managed with nonsteroidal anti-inflammatory drugs and vocal rest for 5 days, achieving complete resolution of symptoms in 10 days. The patient has not had another episode at the 3-month follow-up. 


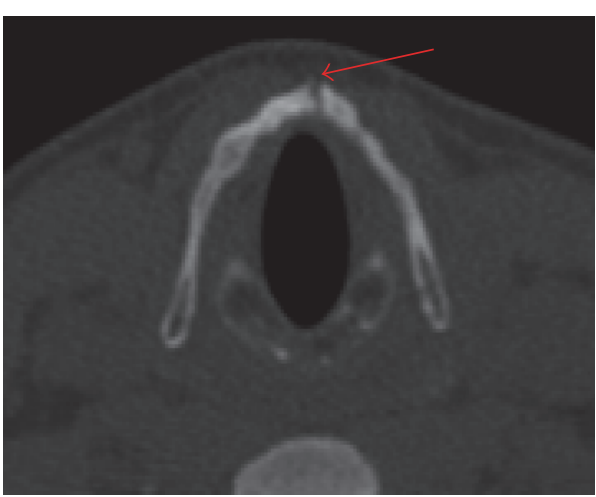

(a)

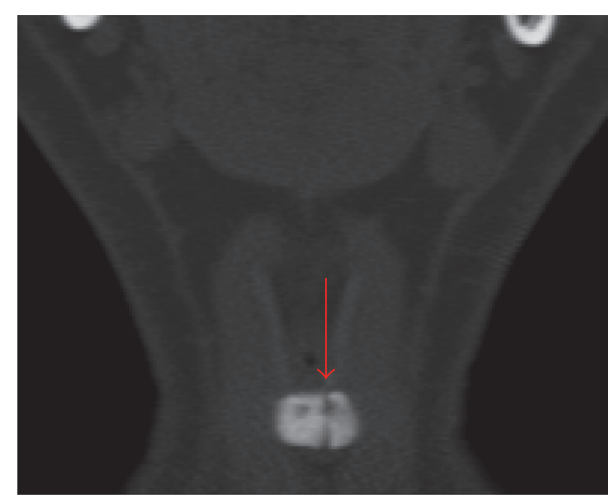

(b)

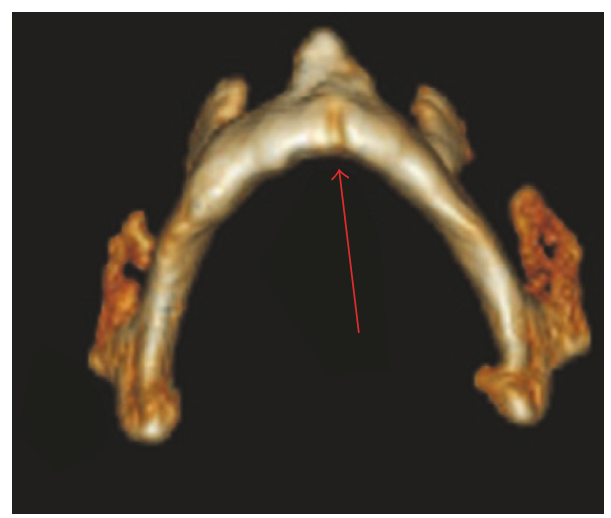

(c)

FIGURE 1: Computed tomography, bone window. Left, complete, and nondisplaced parasagittal fracture that compromises thyroid cartilage (red arrows). (a) Axial view; (b) coronal view; (c) 3D bone reconstruction.

\section{Discussion}

Nontraumatic laryngeal fractures are a rare pathology, with only 4 cases published in the literature, all of which are isolated case reports [2-5]. Our series is the first to bring two cases treated in the same center.

All the published cases correspond to men without a prior morbid or surgical history with a mean age of 40 years (range 29-47 years) [5]. Our two cases were men of 36 and 32 years, respectively.

Its etiology is still unknown. A congenital anomaly of the laryngeal cartilage is proposed, associated with an alteration in the mineralization and ossification, producing sites of focal weakness that predisposes them to develop fractures [4]. However, due to the small number of cases, this has not been demonstrated.

Clinically, the patients presented with the symptomatic triad of dysphonia, dysphagia, and odynophagia initiated after a precipitating event. The precipitating events described in the literature are sneezing attacks in two cases $[2,3]$ and after coughing in the other two cases $[4,5]$. All patients reported having experienced a crack after the precipitating event, followed by the clinical manifestations described. The physical examination highlights the pain over the thyroid cartilage [2-5] and the presence of subcutaneous emphysema $[2,4]$. In our cases the symptomatic triad was presented in one case and in the other only odynophagia and dysphonia; both reported having felt a crack at the beginning of the symptomatology. As for the precipitating event, in one case it was a sneeze and the other was after swallowing while bending down with the neck in flexion, this being the only case described triggered by this mechanism.

It is fundamental to perform a nasopharyngolaryngoscopy and a neck computed tomography to confirm the diagnosis [3-5]. These exams were performed in all cases, except the first one described in the literature in 1950 [2], where these exams were not available. This patient was evaluated by direct laryngoscopy and chest X-ray [2]. The most frequent endoscopic findings were edema and unilateral vocal fold hematoma with preserved vocal fold movement [5]. In the computed tomography, subcutaneous emphysema was evidenced, nondisplaced, or mildly displaced laryngeal fractures, and in one case a phlegmon was also observed; in this case the patient was coursing a high respiratory infection at the time of fracture [5]. Table 1 summarizes the findings of all cases published in the literature plus our two cases.

The treatment basically consists of observation, antiinflammatory, and vocal rest, achieving complete resolution of the symptoms between 14 and 21 days. A single case received antibiotics because it was associated with a cervical phlegmon. As all fractures were not displaced or mildly displaced, none required reduction with titanium plates [5]. 


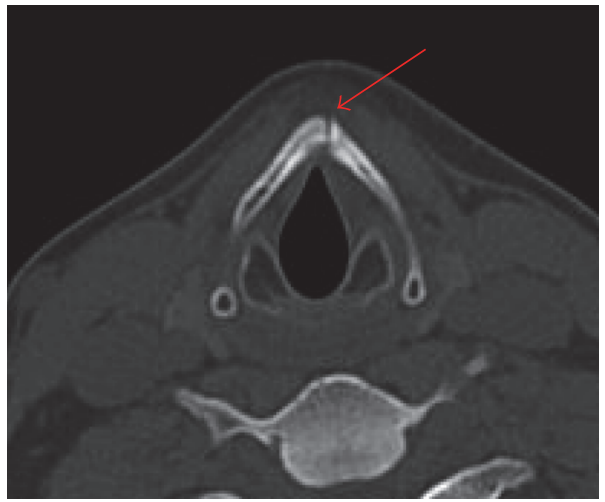

(a)

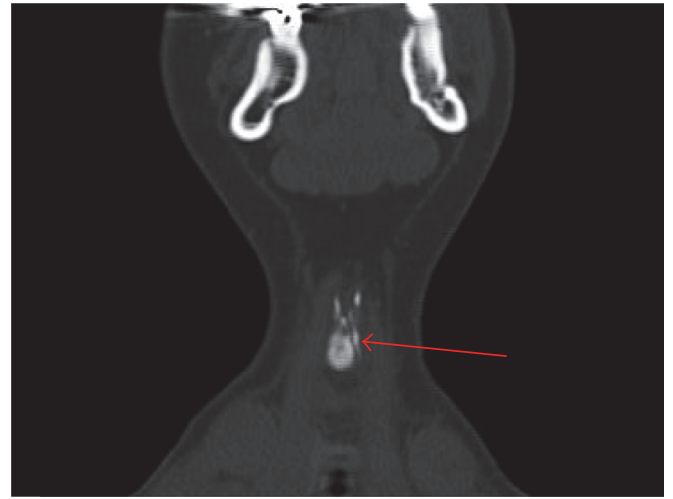

(b)

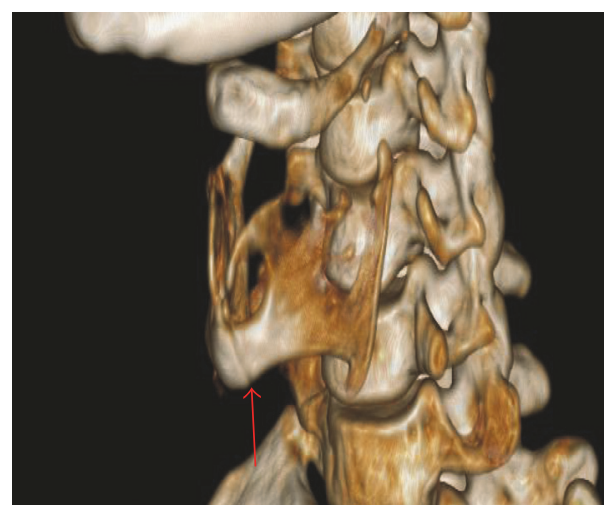

(c)

FIGURE 2: Computed tomography, bone window. Left, complete, and nondisplaced parasagittal fracture that compromises thyroid cartilage (red arrows). (a) Axial view; (b) coronal view; (c) 3D bone reconstruction.

TABLE 1: Symptoms, signs, and endoscopic and imaging findings among patients with nontraumatic laryngeal fracture.

\begin{tabular}{|c|c|c|c|c|c|c|}
\hline & Case 1 [2] & Case $2[3]$ & Case 3 [4] & Case 4 [5] & Case 5 & Case 6 \\
\hline Age/sex & $44 /$ male & 29/male & 41/male & 47/male & $36 /$ male & $32 /$ male \\
\hline Precipitating event & Sneeze & Sneeze & Cough & Cough & Sneeze & $\begin{array}{c}\text { Swallowing and } \\
\text { bending over }\end{array}$ \\
\hline Symptoms/signs & $\begin{array}{c}\text { Odynophagia, } \\
\text { dysphagia, } \\
\text { dysphonia. } \\
\text { Pain and crepitus } \\
\text { over the thyroid } \\
\text { cartilage }\end{array}$ & $\begin{array}{c}\text { Odynophagia } \\
\text { and } \\
\text { dysphonia }\end{array}$ & $\begin{array}{l}\text { Odynophagia, } \\
\text { dysphagia, } \\
\text { dysphonia. } \\
\text { Crepitus over the } \\
\text { thyroid cartilage }\end{array}$ & $\begin{array}{l}\text { Odynophagia, } \\
\text { dysphagia, } \\
\text { dysphonia. } \\
\text { Pain over the } \\
\text { thyroid cartilage }\end{array}$ & $\begin{array}{l}\text { Odynophagia and } \\
\text { dysphonia. } \\
\text { Pain over the } \\
\text { thyroid cartilage }\end{array}$ & $\begin{array}{l}\text { Odynophagia, } \\
\text { dysphagia, } \\
\text { dysphonia. } \\
\text { Pain over the } \\
\text { thyroid cartilage }\end{array}$ \\
\hline Laryngoscopy & $\begin{array}{l}\text { Supraglottic } \\
\text { edema, normal } \\
\text { vocal fold } \\
\text { movement }\end{array}$ & $\begin{array}{l}\text { Right true } \\
\text { vocal fold } \\
\text { edema, } \\
\text { mucosal } \\
\text { hematoma, } \\
\text { normal vocal } \\
\text { fold } \\
\text { movement }\end{array}$ & $\begin{array}{l}\text { Left true vocal fold } \\
\text { hematoma, left } \\
\text { ventricular edema, } \\
\text { normal vocal fold } \\
\text { movement }\end{array}$ & $\begin{array}{l}\text { Edema of right } \\
\text { aryepiglottic fold } \\
\text { and both } \\
\text { arytenoids, normal } \\
\text { glottis, normal } \\
\text { vocal fold } \\
\text { movement }\end{array}$ & $\begin{array}{l}\text { Left vocal fold } \\
\text { hematoma, normal } \\
\text { vocal fold } \\
\text { movement }\end{array}$ & $\begin{array}{l}\text { Supraglottic } \\
\text { edema, normal } \\
\text { vocal fold } \\
\text { movement }\end{array}$ \\
\hline $\begin{array}{l}\text { Computed } \\
\text { tomography (CT) }\end{array}$ & Not available & $\begin{array}{l}\text { Nondisplaced } \\
\text { anterior } \\
\text { fracture, } \\
\text { subcutaneous } \\
\text { air }\end{array}$ & $\begin{array}{l}\text { Mildly displaced } \\
\text { anterior fracture, } \\
\text { subcutaneous air }\end{array}$ & $\begin{array}{l}\text { Mildly displaced } \\
\text { anterior fracture, } \\
\text { subcutaneous air. } \\
\text { Phlegmon } \\
\text { formation }\end{array}$ & $\begin{array}{l}\text { Left parasagittal, } \\
\text { complete } \\
\text { nondisplaced } \\
\text { thyroid cartilage } \\
\text { fracture }\end{array}$ & $\begin{array}{l}\text { Left parasagittal, } \\
\text { complete } \\
\text { nondisplaced } \\
\text { thyroid cartilage } \\
\text { fracture }\end{array}$ \\
\hline
\end{tabular}




\section{Conclusion}

Nontraumatic laryngeal fracture is a rare condition, affecting men between the third and fifth decade of life, which should be suspected in patients with the symptomatic triad of odynophagia, dysphagia, and dysphonia abruptly initiated after a precipitating event such as coughing or sneezing. Clinical suspicion, endoscopy, and imaging are fundamental for diagnosis.

\section{Conflicts of Interest}

The authors declare that there are no actual or potential conflicts of interest in relation to this article.

\section{References}

[1] M. Menard, O. Laccourreye, and D. Brasnu, "Traumatismos externos de laringe," in Encyclopédie Médico-Chirurgicale, p. 20-720-A-10, Editions Scientifiques et Médicales Elsevier SAS, Paris, France, 2002.

[2] P. T. Quinlan, "Fracture of thyroid cartilage during a sneezing attack," British Medical Journal, vol. 1, no. 4661, p. 1052, 1950.

[3] A. Beato Martínez, Á. M. Juara, and J. J. López Moya, "Fracture of thyroid cartilage after a sneezing episode," Acta Otorrinolaringologica Espanola, vol. 58, no. 2, pp. 73-74, 2007.

[4] V. R. C. Alexander and S. Toynton, "Spontaneous fracture of the larynx after coughing," Otolaryngology-Head and Neck Surgery, vol. 147, no. 4, pp. 801-802, 2012.

[5] M. Fenig, S. Strasberg, J. C. Cohen, R. Almadi, and M. Gold, "Laryngeal fracture after coughing," American Journal of Emergency Medicine, vol. 31, no. 9, pp. 1421.e1-1421.e3, 2013. 


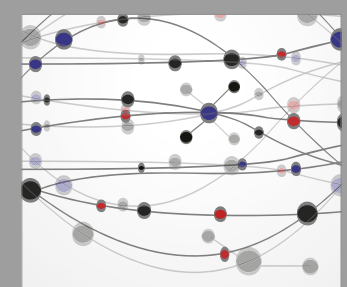

The Scientific World Journal
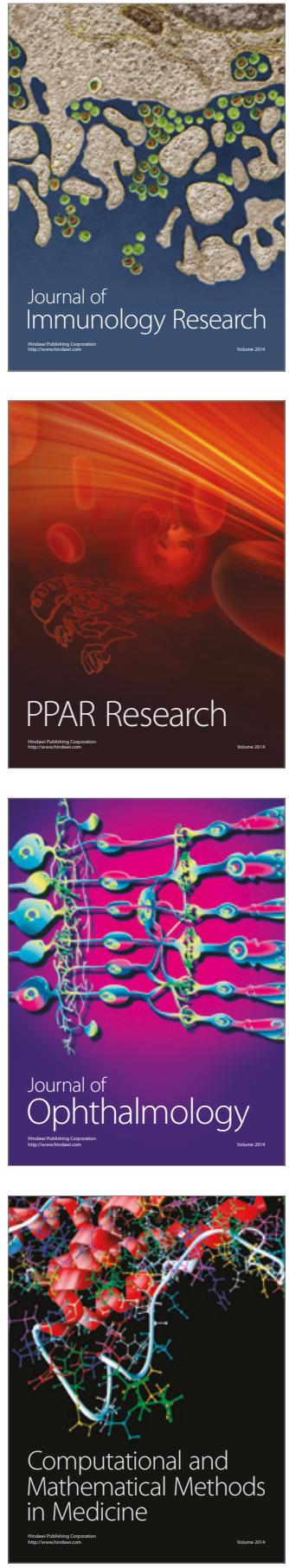

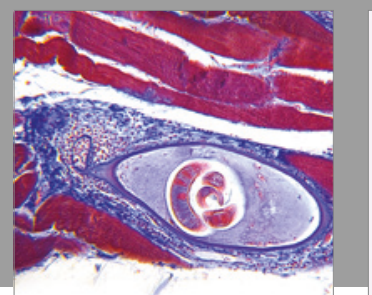

Gastroenterology Research and Practice
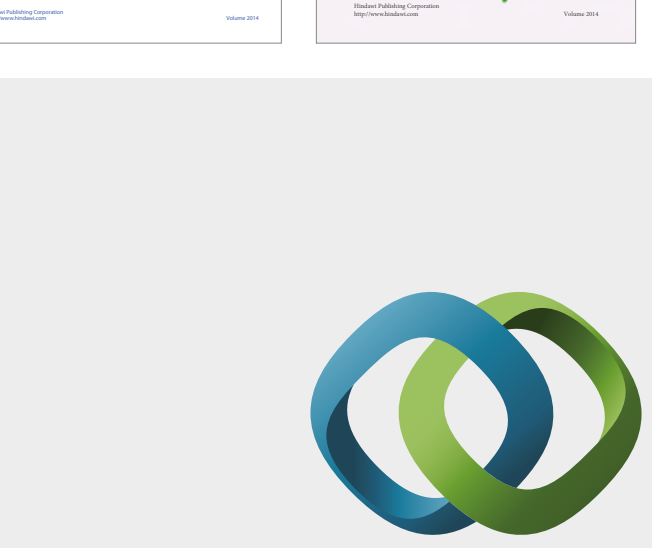

\section{Hindawi}

Submit your manuscripts at

https://www.hindawi.com
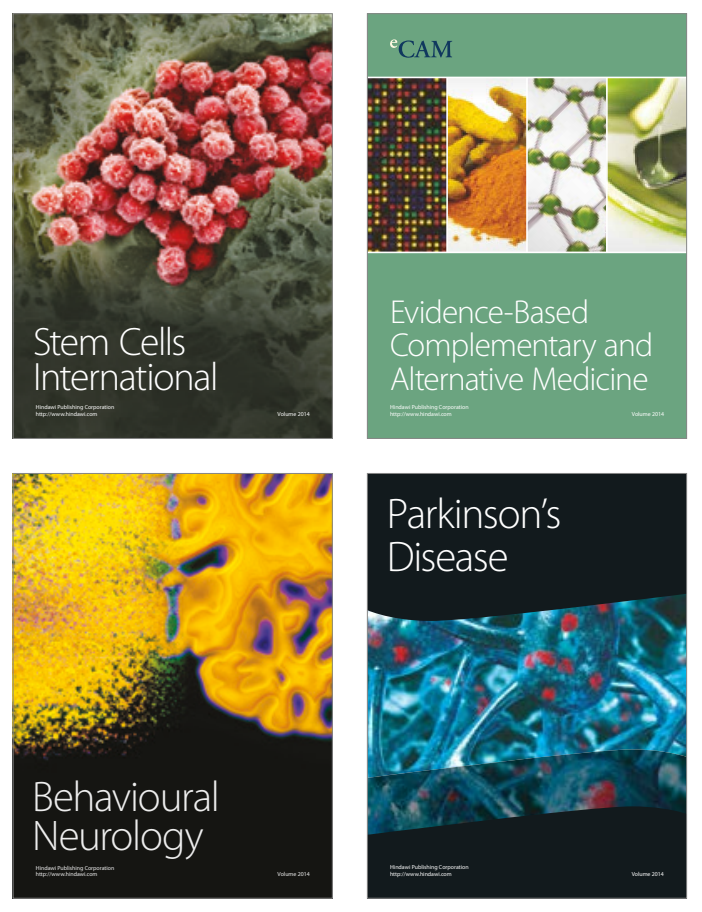
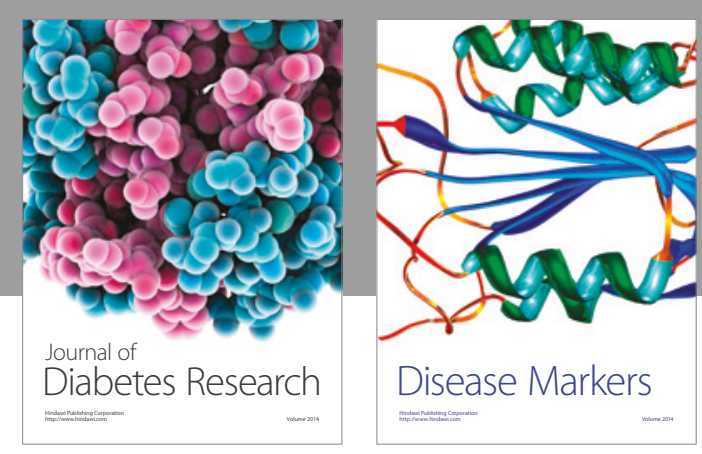

Disease Markers
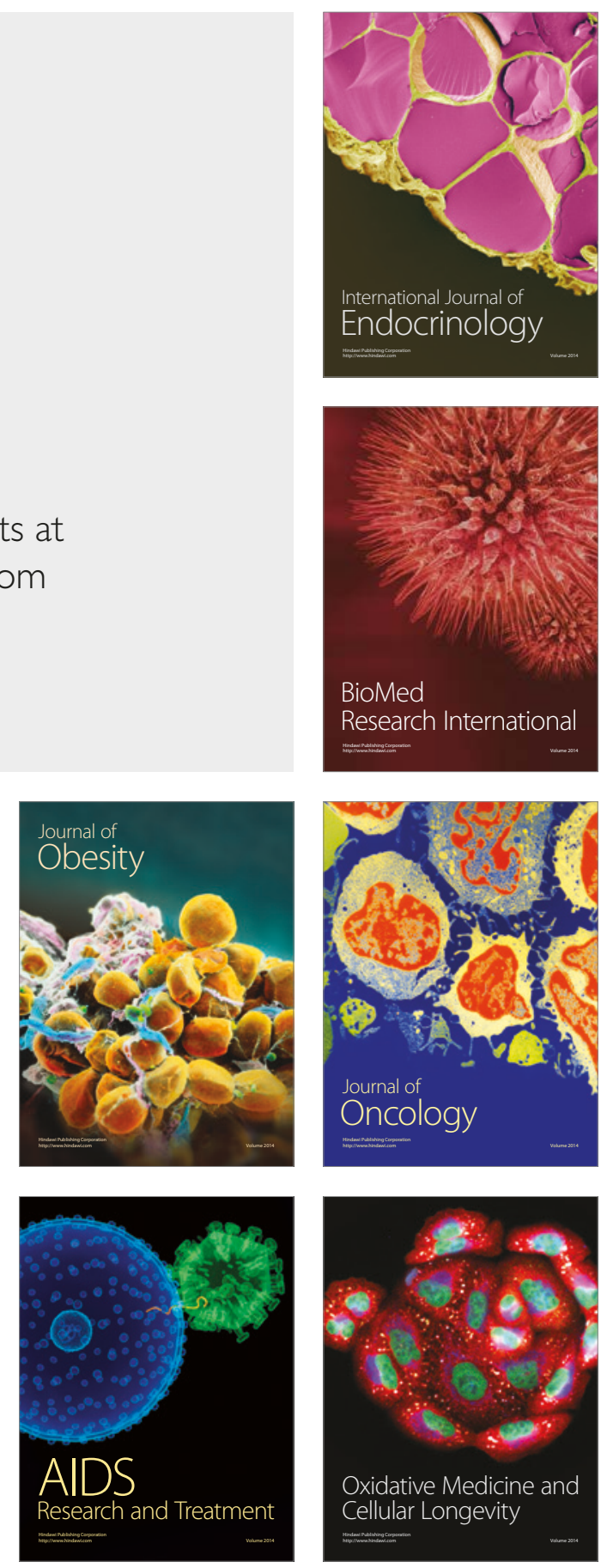